\title{
Investigating the midwives' knowledge on infant and young child feeding during the COVID-19 pandemic
}

\author{
Nuril Annissa Niswanto ${ }^{1 *}$,Nasaruddin Nasaruddin ${ }^{2}$, and Marthoenis Marthoenis ${ }^{3}$ \\ ${ }^{1}$ Department of Disaster Science, Post Graduate School, Universitas Syiah Kuala, Banda Aceh 23111, Indonesia \\ ${ }^{2}$ Department of Electrical \& Computer Engineering, Engineering Faculty, Universitas Syiah Kuala, Banda Aceh 23111, Indonesia \\ ${ }^{3}$ Department of Psychiatry and Mental Health Nursing, Nursing Faculty, Universitas Syiah Kuala, Banda Aceh 23111, Indonesia
}

\begin{abstract}
Implementing the WHO gold standards for Infant \& Young Child Feeding (IYCF) may help in preventing stunting, which may worsen during Covid-19 Pandemic. Midwives can help educating the mother in proper child feeding. This research aimed to assess the knowledge of midwives working in the community on IYCF during Covid-19. A total of 88 midwives working in various healthcare facilities participated in this study. Using online survey methods, they were invited to answers questions that measure their knowledge on basic practices of IYCF, Covid-19 transmission risk in breastfeeding dyads, breastfeeding practices, and complementary feeding during the pandemic. It was found that the rate of good, moderate and poor knowledge on IYCF during Covid- 19 Pandemic were $23 \%, 67 \%$ and $19 \%$, respectively. In conclusion, less than one third of the respondents showed good knowledge - something requiring investigation on the strategies to build stronger capacity of midwives in terms of IYCF during Covid-19 Pandemic.
\end{abstract}

\section{Introduction}

A community incapable of understanding - thus ensuring the optimal practices of - IYCF before a crisis/emergency takes place would only accelerate "the secondary crisis" during the phase of the early emergency response of a disaster [1]. Aceh is at stake as the pre-Pandemic data showed that the prevalence of stunting in Aceh had shown an alarming number of $37.9 \%$ compared to the national average of $29.9 \%$ [2]. Aceh is a province with the highest prevalence of stunting in Indonesia in infants under two years of age, "conquering" the provinces of Papua, Maluku and other Eastern regions [3].

The prevalence of stunting in Aceh, which was still above $30 \%$ in the $2007-2018$ period fell into the very high and high categories. Even without an emergency or disaster, Aceh already faced nutrition problems - a dangerous predisposition to a worsening malnutrition problem during a crisis we are all facing today; the Covid-19 Pandemic. Children who faced and survived events of malnutrition might lose certain cognitive traits so permanent it could be inherited to the next generations genetically [4]. Hence, the proper practices of IYCF during the Pandemic, among multiple other factors, may avert the stunting cases in the future.

The proper practices of Infant \& Young Child Feeding (IYCF) in Emergencies (or often referred to as IYCFE) could save the infant and young children from infectious illnesses or even death threats [5]. IYCF (early breastfeeding initiation, exclusive breastfeeding 0-6 months old, complimentary solid feeding since the age of 6 months, while continuing the breastfeeding up until 2 years of age or more) needs to be addressed in any emergencies - including Covid-19 Pandemic - for infants and young children. They are amongst the vulnerable groups to a following "secondary crisis" in the form of acute malnutrition, which may end with death when not treated properly [6].

\subsection{IYCF during Covid-19 pandemic}

The National Health Ministry has stated that there has been no change in IYCF recommendations during the Covid-19 Pandemic, which is aligned to the WHO [7]. Mothers with confirmed cases of Covid-19 should continue to breastfeed and or provide complimentary home-cooked foods while maintaining the correct health protocols; by washing hands before and after contact with their babies or the food preparation processes, wearing masks all the time when being present with the babies/children, and sanitizing all surfaces periodically [8]. The risk - and fear - of children contracting Covid19 is outweighed by the abundant benefits of ensuring the IYCF practices during this pandemic. The correct IYCFE could actually help increase the children's immunity [9] and prevent malnutrition from happening during and after the pandemic ends [10].

\subsection{Midwives, IYCF, and Covid-19 pandemic}

Midwives possess accessibilities in educating the communities about disaster/emergency preparedness

\footnotetext{
*Corresponding author: nuril.an@unsyiah.ac.id
} 
and other disaster risk reduction actions. Midwives are encouraged by The International Confederation of Midwives (ICM) to contribute in managing a disaster including a pandemic - particularly regarding mothers and children's health issues [11].

Midwives are the closest health workers working amongst "end-users" in society, including those stationed in Local Community Health Center or as known as Puskesmas. Every sub district (or more known as "kecamatan") usually is equipped with 1 or 2 Puskesmas, depending on the area width and the population in it.

Midwives stationed in Puskesmas generally serve longer duration of working in the assigned area, thus more frequent interactions with the society. They are amongst the most effective health educators in the grassroots [11], [12]. Thus, their knowledge on IYCF is crucial in running their services and for the stakeholder to have a better foundation for trainings needed to improve their capacity, especially during the on-going pandemic. However, data regarding the implementation of IYCFE in the midst of the Covid-19 pandemic is not yet available. Hence this study aimed to get the picture on where the midwives were with IYCF during Covid19 Pandemic.

Identifying the current knowledge status will benefit the related stakeholders for better capacity building on IYCF practices. This, hopefully, will clear the way for the stakeholders to build stronger capacity of the midwives as one of the many ways to decrease the stunting prevalence in Aceh during or after the pandemic ends.

\section{Methods}

\subsection{Study setting}

The study was conducted in the city of Banda Aceh City, the capital of Aceh Province. The city has been stated as red zones due to high number of Covid-19 cases in Aceh for several times. The infection had been widely spread within the population, including breastfeeding mothers or those taking care of a child aged 0-2-year-old. Hence, correct understanding on IYCF plays a significant role for the healthcare workers - including midwives - to protect the IYCF practices during this challenging time.

Banda Aceh has 11 Puskesmas [13] where more than 100 midwives are in contact with women and children within Banda Aceh.

\subsection{Study design}

This cross-sectional study was conducted among midwives with close contact to mothers and children under 2-year-old in all Puskesmas in the city of Banda Aceh. A Google form was developed to collect data on the demographic information and their knowledge on the IYCF. The survey questions were constructed based on the IYCF guidelines both the international and national ones on IYCF Practices during Covid-19 Pandemic [9]-[15]. The knowledge obtained was aimed at several aspects related to the IYCF during Covid-19
Pandemic consisting of their knowledge on basic practices of IYCF, Covid-19 transmission risk in breastfeeding dyads, breastfeeding practices - in general, breast milk expression, and breast milk substitution - and complementary feeding during the pandemic.

The surveys consist of 54 true-or-false statements in total that were given to the subjects in randomized order. The questions were designed so that every question needed to be filled for the survey to conclude. The researcher asked for participants' written consent beforehand the surveys were done during a non-working day simultaneously in limited time to prevent information-sharing during the surveys.

\subsection{Data collection \& management}

Data were collected directly from the electronic forms filled by the participants via Google Form platforms. Data were anonymized, and the original data were stored separately on an encrypted hard storage device. The results of the study were informed as a compiled and processed data for the respondents.

\section{Results \& discussion}

\subsection{Characteristics of respondents}

All 11-community health centres or Puskesmas in Banda Aceh City were planned to be involved in this study. However, in the course of the research, several respondents from one of the Puskesmas turned out to have just started self-isolation due to Covid-19. In order to respect the healing time of the respondents infected with Covid-19 with mild-moderate symptoms, the researchers excluded 1 Puskesmas thus leaving only 10 Puskesmas to be included in the study. All respondents were $100 \%$ all-female with the following characteristics:

Table 1. Respondents' characteristics of the Study.

\begin{tabular}{|c|c|c|}
\hline Characteristic & $\begin{array}{c}\text { Sub } \\
\text { Characteristic }\end{array}$ & $\begin{array}{c}\% \\
(\mathrm{n}=88)\end{array}$ \\
\hline \multirow{2}{*}{ Age Groups } & $\begin{array}{c}30-40 \text {-year- } \\
\text { old }\end{array}$ & $55 \%$ \\
\cline { 2 - 3 } & $>40$-year-old & $45 \%$ \\
\hline \multirow{3}{*}{ Education } & Diploma & $76 \%$ \\
\cline { 2 - 3 } & $\begin{array}{c}\text { Graduate/ } \\
\text { Postgrad }\end{array}$ & $24 \%$ \\
\hline \multirow{3}{*}{$\begin{array}{c}\text { Working } \\
\text { Period }\end{array}$} & $1-5$ years & $3 \%$ \\
\cline { 2 - 3 } & $5-10$ years & $15 \%$ \\
\cline { 2 - 3 } & $>10$ years & $82 \%$ \\
\hline
\end{tabular}

Most of the respondents were senior in terms of working years and age, yet the results showed that only $23 \%$ of the respondents possessed good knowledge of IYCF during Covid-19 Pandemic while the remaining showed moderate and poor knowledge. 


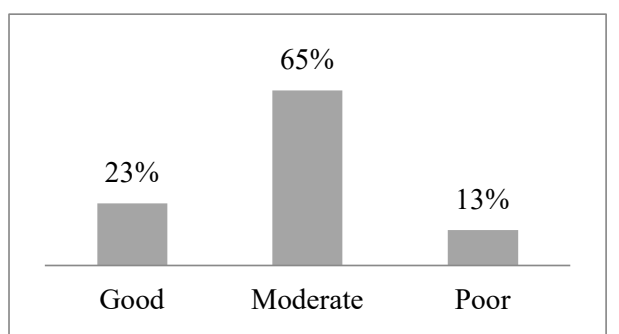

Fig. 1. Respondents' knowledge on IYCF during Covid-19 pandemic in general.

\subsection{Deciphering Midwives' knowledge on IYCF during Covid-19 pandemic}

Table 2. Midwives' Knowledge on IYCF during Covid-19 Pandemic.

\begin{tabular}{|c|c|c|c|c|}
\hline Knowledge Level & वे & $\frac{3}{\frac{2}{2}}$ & $\stackrel{0}{\circ}$ & $\frac{\substack{2 \\
2}}{2}$ \\
\hline $\begin{array}{c}\text { IYCF Basic } \\
\text { Principles }\end{array}$ & $17 \%$ & $77 \%$ & $6 \%$ & $0 \%$ \\
\hline $\begin{array}{c}\text { Covid-19 } \\
\text { Transmission } \\
\text { Risk in } \\
\text { Breastfeeding } \\
\text { Dyads } \\
\end{array}$ & $41 \%$ & $31 \%$ & $17 \%$ & $11 \%$ \\
\hline $\begin{array}{l}\text { Health Protocols } \\
\text { of A Mother with } \\
\text { Covid-19 }\end{array}$ & $38 \%$ & $40 \%$ & $18 \%$ & $5 \%$ \\
\hline $\begin{array}{c}\text { Breast Milk } \\
\text { Substitutes when } \\
\text { Breastfeeding Not } \\
\text { Possible }\end{array}$ & $15 \%$ & $50 \%$ & $18 \%$ & $17 \%$ \\
\hline $\begin{array}{c}\text { Managing } \\
\text { Complimentary } \\
\text { Foods during } \\
\text { Covid-19 } \\
\text { Pandemic }\end{array}$ & $72 \%$ & $26 \%$ & $2 \%$ & $0 \%$ \\
\hline
\end{tabular}

The results showed that there were less than one fifth or only $17 \%$ were within good knowledge on basic principles of IYCF in general. This might be due to more than half of them (68\%) never received the neededtraining in IYCF before. Only one third or $32 \%$ of the respondents stated that they had the training once by UNICEF in the past before the Pandemic started. The results might also be caused by more work was emphasized into infection control and prevention of Covid-19, and not as much onto the other supporting factors such as nutrition or IYCF. Having stakeholders - including health workers such as midwives - with a non-adequate capacity of understanding issues related to nutrition such as IYCF during non-disaster contexts could lead to even worse nutritional statuses when in an emergency situation [1].

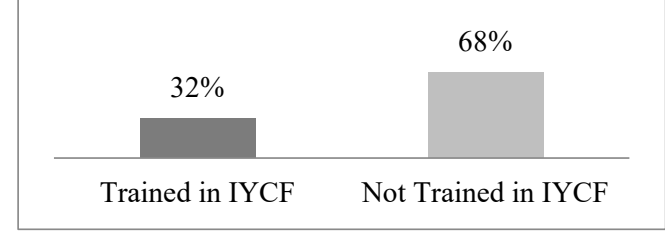

Fig. 2. Respondents' training experiences on IYCF.

Almost half or $41 \%$ of the respondents were having good knowledge on Covid-19 Transmission Risk in Breastfeeding Dyads. The remaining majority showed moderate knowledge $(31 \%)$ while the rest were still showing poor and very poor scores. This might be caused by the few or no contacts some of them had been having with such scenarios in their real work life during the Pandemic. Only $6 \%$ of the respondents encountered pregnant/breastfeeding mothers and infant with Covid19 from period March 2020 up until June 2021.

During this Covid-19 pandemic in which the virus easily transmitted via air droplets, breastfeeding is still highly supported to be continued by the WHO anytime an infected mother is fit enough to nurse [16]. This is based upon weighing the abundant benefits of continuing breastfeeding over the risk of Covid-19 transmission in which experts stated that mother-child dyads separation is not the answer to it [17].

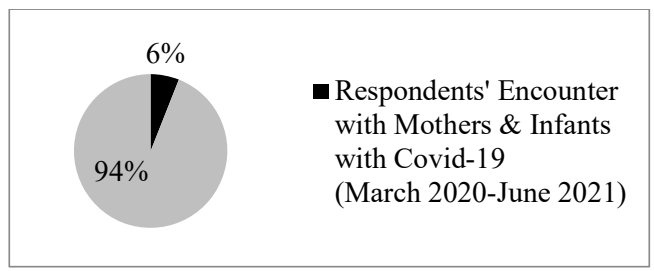

Fig. 3. Respondents' Encounter with Mothers \& Infants with Covid-19 (March 2020 - June 2021).

Midwives are among health workers that are often asked for their opinion on maternal and child health, especially during this Pandemic. Having knowledge about the health protocol of breastfeeding mothers suspected of or confirmed positive for Covid-19 is an important capacity for the midwives on advising/counselling mothers with the condition.

There were less than half or only $38 \%$ of the subjects showed good knowledge of the health protocols recommendations for when a mother with Covid-19 infection wills to breastfeed. This is a critical point in which the $6 \%$ of the respondents who stated that they had encountered mothers with Covid-19 might have had counselled their patients poorly on IYCF.

Breastfeeding mothers with COVID-19 in a stable condition are to be counselled to continue breastfeeding their babies $[8,9,14]$. However, infection control efforts should still be maintained through health protocols in accordance with existing recommendations $[15,16]$. These precautions need to be taken into accounts in order to minimize the risk of transmission while still promoting breastfeeding for the breastfeeding dyads with Covid-19 [10].

When breastfeeding is not possible, alternatives or substitutions should still be given, especially for babies 
under 6 months of age who are not suitable of solid foods. However, giving alternative or inappropriate breast milk substitutes such as the incorrect preparation for formula feeding will only yield "new disasters" in the form of threats of infection or even death [5]. Expressed breast milk remains the first priority if the mother cannot breastfeed directly. Expressed breast milk is proven not to transmit Covid-19 [17]. Even more beneficial for the infants consuming them, expressed breast milks from mothers with Covid-19 are proven to contain antibodies against SARS Cov-2 that will protect the infants - which is not found in formula milk [18]. It is important for health workers, including respondents of this study, to have this knowledge in order to be able to properly inform the public on the matter.

Unfortunately, only $15 \%$ of the respondents obtained good scores of knowledges on handling breast milk substitution when the direct breastfeeding is not possible. Improper handling of breast milk substitute such as improper preparation of formula feeding could cause malnutrition or worse - infection or even death when not handled correctly [19]. This might be due to the incomplete understanding of IYCF practices. Highlights of IYCF generally are placed upon breastfeeding and less on how to handle the unimaginable non-ideal situations previously. Today, situations such as when a mother died of Covid-19 and no other breast milks are available to feed the child with, has been "normal news" during Pandemic. Incomplete understanding of IYCF, including on when and how to prepare breast milk substitutes, could lead to possible cases of infection and worsening nutritional status.

For example, there were $8 \%$ of the respondents who had experienced suggesting breast milk substitutes to their patients without necessarily assisting them with the proper dosages, methods and risks attached to the product consumption. The listed reasons were merely converging into one excuse of "the patients complained of not having enough breast milks". Detailed indications for the breastfeeding could actually take place. The indications are usually diagnosed by medical specialists for medical conditions preventing mothers to breastfeed such as several cases of mothers' poor mental health status or proof of baby's dehydration or the malnutrition status in need of fast catching up and a bucket of other legitimate causes.

In addition to breastfeeding, appropriate complementary feeding according to $\mathrm{WHO}$ and Ministry of Health guidelines needs to be continued. The Covid-19 pandemic itself has made conditions for many families economically difficult which has the potential to contribute to the risk of malnutrition cases [20]. Thus ensuring the continuation of proper complimentary food management in an emergency including this pandemic - as much as possible is one of the keys to preventing the decline in children's nutritional status [21].

Almost two thirds or $72 \%$ of them showed good scores of knowledge in preparing complimentary foods safely with the suitable infection control precautions even when the caretakers are infected by Covid- 19 . These results are "fresh air" at the end of the surveys, where possible good practices of safe complementary feeding were already established pre-pandemic thus continued to reside as good knowledge on the matter.

\section{Conclusion}

In conclusion, there are less than one third of the respondents that showed good knowledge on IYCF during Covid-19 Pandemic in general. More than half of them possessed moderate and poor knowledge something that needs a further investigation on the underlying causes and the strategies needed to build even stronger capacity of midwives in terms of IYCF during Covid-19 Pandemic. There were clearly rooms for improvement for these not-yet-trained midwives that can be filled from other sources of information upgrading and capacity building on the matter.

This pandemic seems to not cease in near future. Thus, giving more attention on the correct knowledge on IYCF practices particularly during Covid-19 Pandemic not only has the potential to strengthen their immunities to survive the pandemic, but also help them grow well even after the pandemic is contained or even better, ended. These study results may serve as the ground to better understanding on how to develop programs to prevent the stunting cases from re-emerging or worse, sky-rocketing during or after this Covid-19 Pandemic ends.

\section{References}

1. D. de Rosari and A. Saepudin, 17, (2013)

2. Pemerintah Aceh, (2019)

3. Kementerian kesehatan Repubelik Indonesia, (2018)

4. C. M. Jacob, D. D. Briana, G. C. Di Renzo, N. Modi, F. Bustreo, G. Conti, A. MalamitsiPuchner, and M. Hanson, The Lancet Public Health 2667, 19 (2020)

5. T. L. Creek, A. Kim, L. Lu, A. Bowen, J. Masunge, W. Arvelo, M. Smit, O. MacH, K. Legwaila, C. Motswere, L. Zaks, T. Finkbeiner, L. Povinelli, M. Maruping, G. Ngwaru, G. Tebele, C. Bopp, N. Puhr, S. P. Johnston, A. J. Dasilva, C. Bern, R. S. Beard, and M. K. Davis, Journal of Acquired Immune Deficiency Syndromes 53, 14 (2010)

6. K. Gribble, Journal of Human Lactation 34, 40 (2018)

7. Kemenkes RI and United Nations Indonesia, Kesmas: National Public Health Journal 1, 1 (2020)

8. WHO, 1 (2020)

9. C. Tomori, K. Gribble, A. E. L. Palmquist, M. T. Ververs, and M. S. Gross, Maternal and Child Nutrition 16, 1 (2020)

10. W. Lubbe, E. Botha, H. Niela-Vilen, and P. Reimers, International Breastfeeding Journal 15, 82 (2020)

11. N. Hesti, H. Yetti, and E. Erwani, Jurnal Kesehatan Andalas 8, 338 (2019)

12. N. Syamiyah and H. Helda, Jurnal Penelitian Dan Pengembangan Pelayanan Kesehatan 2, 29 (2018) 
13. Kementerian Kesehatan RI, Profil Kesehatan Indonesia Tahun 2019 (2020)

14. D. Vu Hoang, J. Cashin, K. Gribble, K. Marinelli, and R. Mathisen, BMJ Nutrition, Prevention and Health (2020)

15. GKIA and WHO, 1 (2020)

16. Satgas Covid RI, (2020)

17. M. Á. M. Gabriel, A. M. M. Martínez, M. E. M. Martínez, and J. A. Pedroche, Breastfeeding Medicine 15, 492 (2020)

18. G. G. A. Fouda, J. J. Kwiek, and M. Yotebieng, 147, (2021)

19. K. Gribble and C. Fernandes, World Nutrition 9, 261 (2018)

20. D. Headey, R. Heidkamp, S. Osendarp, M. Ruel, N. Scott, R. Black, M. Shekar, H. Bouis, A. Flory, L. Haddad, and N. Walker, The Lancet 396, 519 (2020)

21. P. Codjia, M. Volege, M. T. Le, A. Donnelly, F. F. Sesay, J. V. Senesie, and L. Kiige, Field Exchange 35 (2018) 